\title{
Prevalence of left ventricular geometric patterns in hypertensive patients in Angola
}

\author{
Savarino Victória Pereira ${ }^{1}$, Ana Feijão ${ }^{1}$ and Humberto Morais ${ }^{2 *}$ \\ ${ }^{1}$ Department of Cardiology Service, Hospital Américo Boavida, Avenida Hoji Ya Henda, Luanda, Republic of Angola \\ ${ }^{2}$ Department of Cardiology, Hospital Militar Principal/Instituto Superior, Rua D. Manuel I. Luanda. Republic of Angola
}

\begin{abstract}
Aim: The aim of the present study is to evaluate the prevalence of left ventricular geometric patterns in hypertensive patients in Angola.

Methodology: cross-sectional descriptive observational study performed in two diagnostic centers in Luanda. We included all hypertensive patients who underwent transthoracic echocardiographic study in the 2 nd quarter of 2012 in both centers. The echocardiographic study was performed according to the ASE recommendations. The relative wall thickness and the presence or absence of echocardiographic left ventricular hypertrophy was used to determine the various geometric patterns.

Results: 84 patients were included, 33 males and 51 females, the mean age was 52.7 ( \pm 13.4$)$ years. $49 \%$ had concentric hypertrophy, $20 \%$ had eccentric hypertrophy, and $17 \%$ concentric remodelling and $14 \%$ had normal geometry. Regarding left ventricular function $87 \%$ of had normal systolic function, $64 \%$ had diastolic dysfunction.

Conclusion: The results show that concentric and eccentric hypertrophy is the most frequent geometric patterns. Diastolic dysfunction is present in majority of the patients. The need for longitudinal studies assessing the prognostic value of geometric patterns in hypertensive patients in Angola, as well as their relationship with left ventricular function is imperative.
\end{abstract}

\section{Introduction}

In Angola, systemic arterial hypertension (SAH) is the most frequent chronic non-communicable disease, with an estimated prevalence of $23 \%$ [1]. Left ventricular hypertrophy (LVH) is a known complication of SHA that has long been recognized as an independent risk factor for adverse outcomes in hypertensive patients [2,3]. The various forms of left ventricular (LV) adaptation to uncontrolled hypertension were described in four different geometric patterns using combinations of left ventricular mass index (LVMI) and relative wall thickness (RWT) [4]. They are normal geometry (NG) with LVMI and normal RWT; concentric remodelling (CR) - normal LVMI and increased RWT; eccentric hypertrophy EH - LVMI increase and normal RWT; concentric hypertrophy $(\mathrm{CH})$, with increased LVMI and RWT. Studies have shown that the incidence of cardiovascular events is higher in patients with $\mathrm{CH}$, intermediate in those with $\mathrm{CR}$ and $\mathrm{EH}$ geometric patterns, and lower in patients with NG $[5,6]$. The objective of the present study is to evaluate the prevalence of left ventricular geometric patterns in hypertensive patients in Angola, as well as to describe sociodemographic, clinical and echocardiographic aspects of the study population.

\section{Materials and methods}

Cross-sectional descriptive observational study carried out in two diagnostic centers in Luanda. All hypertensive patients who underwent two-dimensional transthoracic echocardiographic and Doppler study in the $2^{\text {nd }}$ quarter of 2012, in both centers were included. Patients with other non-high blood pressure related heart diseases and patients younger than 18 years were excluded. Sociodemographic, clinical and echocardiographic variables were collected.

\section{Sociodemographic characterization}

The data on age, sex, weight, height and cardiovascular risk factors (CVRF) were recorded on the day when the patients underwent echocardiography. The age and CVRF (family history of hypertension, diabetes mellitus, smoking, sedentary lifestyle and dyslipidemia) were variables based on the interview conducted on the patient. The height and weight were measured by an experienced health professional. The body surface (BS) was calculated by the formula BS=height (m)/ weight $(\mathrm{kg})$ and body mass index (BMI) was calculated by the formula BMI $=$ weight $(\mathrm{kg}) /$ height $2(\mathrm{~cm})$. According to the BMI, patients were classified as underweight: BMI below 18.5, normal weight: BMI between 18.5 and 24.9, overweight: BMI between 25 and 29.9, obesity grade I: BMI between 30 and 34, obesity grade II: BMI between 35 and 39.9 , obesity grade III: $\mathrm{BMI} \geq 40$.

\section{Characterization of arterial hemodynamic}

Systolic blood pressure (SBP) and diastolic blood pressure (DBP) were measured by a specialized healthcare professional minutes before the echocardiographic examination. Blood pressure was measured with the patient sitting in a calm, homeothermic environment, without sound or light pollution and without ingestion or inhalation

${ }^{*}$ Correspondence to: Humberto Morais, Department of Cardiology, Hospital Militar Principal/Instituto Superior, Rua D. Manuel I. Luanda, Republic of Angola, Tel: +244923520937, E-mail: hmorais1@gmail.com

Key words: systemic arterial hypertension, left ventricular geometry, transthoracic echocardiography

Received: March 01, 2019; Accepted: March 11, 2019; Published: March 18, 2019 
of exciting products (such as caffeine, alcohol, tobacco) in the 15 to 30 minutes preceding the measurement. For this purpose, SBP and DBP were measured using an aneroid sphygmomanometer, according the Korotkoff method (k1 to k5 sounds, respectively).

The variable "control of hypertension" was based on the analysis of the BPs assessed, being considered controlled whenever SBP $<140$ and $\mathrm{DBP}<90 \mathrm{mmHg}$. If SBP $\geq 140$ and $\mathrm{DBP} \geq 90 \mathrm{mmHg}$, hypertension was considered uncontrolled. In patients with renal impairment and / or diabetes, hypertension was considered controlled only with $\mathrm{SBP}<130$ and DBP $<80 \mathrm{~mm} \mathrm{Hg}$.

The time of diagnosis of hypertension was divided into "diagnosis for less than 1 year", "diagnosis between 1 and 5 years" and "diagnosis for more than 5 years". In this way, we can evaluate whether there is a recent (less than 1 year), intermediate ( 1 and 5 years) or long (more than 5 years) diagnosis with all the physiological changes that such a difference entails.

\section{Two-dimensional transthoracic echocardiography}

Two-dimensional transthoracic echocardiography (TTE) and the Doppler study were performed according to the Guidelines of the American Society of Echocardiography $[7,8]$. The thickness of the interventricular septum (IVST), the thickness of the posterior wall (PWT), and the diastolic diameter of the left ventricular (LVDD) were measured in the telediastole; the left ventricle systolic diameter (LVSD) on the telesystole. All of these measurements were made in M-mode, guided by two-dimensional echocardiography (Figure 1A). LV mass (LVM) was calculated by the formula: MVE $=0.8 \times\{1.04$ [(DTDVE + PWT+ SIVT) 3 - (DTDVE) 3]) + 0.6 (). The LVM index (LVMI) was calculated by the formula LVMI $=$ LVM/BS [9]. The LVMI was considered normal when $\leq 134 \mathrm{~g} / \mathrm{m}^{2}$ and $\leq 110 \mathrm{~g} / \mathrm{m}^{2}$ for men and women respectively [10]. Relative wall thickness (RWT) was calculated according to the following formula: RWT $=2 \mathrm{xPWT} / \mathrm{LVDD}$. RWT was considered normal when $\leq 0.42[7]$.

The geometric patterns of the left ventricle were defined as follows: NG with normal RWT and LVMI; cardiac remodelling CR - RWT is increased but LVMI is normal; EH - RWT is normal but LVMI is increased; CH - RWT and LVMI are increased.

Left atrial volume was calculated by the Simpson method in apical of 2 and 4 chambers, making a volumetric mapping of the left atrium, and it was indexed to BS. The left ventricular shortening fraction (SF) was calculated by the following formula: SF $=($ LVDD - LVDD) $/$ LVDD $\mathrm{x} 100$. The left ventricular ejection fraction (LVEF) was calculated by the Simpson method. The left ventricular systolic function was classified into 4 types: preserved if LVEF $\geq 55 \%$, slightly compromised if LVEF was between $45-54 \%$, moderately compromised if LVEF is between 30 $44 \%$ and severely compromised if LVEF $<30 \%$ [7].

Left ventricular filling was assessed by recording mitral flow by standard pulse Doppler technique, and the following parameters were considered: early diastolic peak flow velocity (E), late diastolic peak flow velocity (A) and the ratio of the early to late flow velocity peaks (E/A ratio) (Figure 1B). Pulsed-wave tissue Doppler imaging was used to measure early diastolic peak wave velocity (e'), and late diastolic peak velocity wave (a') with the cursor placed over the septal and lateral mitral annulus (Figures 1C and 1D). In addition, using the mean early diastolic peak wave velocity e' of both sites of the mitral annulus the early diastolic peak flow velocity to early diastolic peak wave velocity (E/e') ratio were calculated. Diastolic function was classified into 5 types: normal diastolic function, mild diastolic dysfunction (DD), moderate DD (pseudo-normal or DD grade II), severe DD restrictive

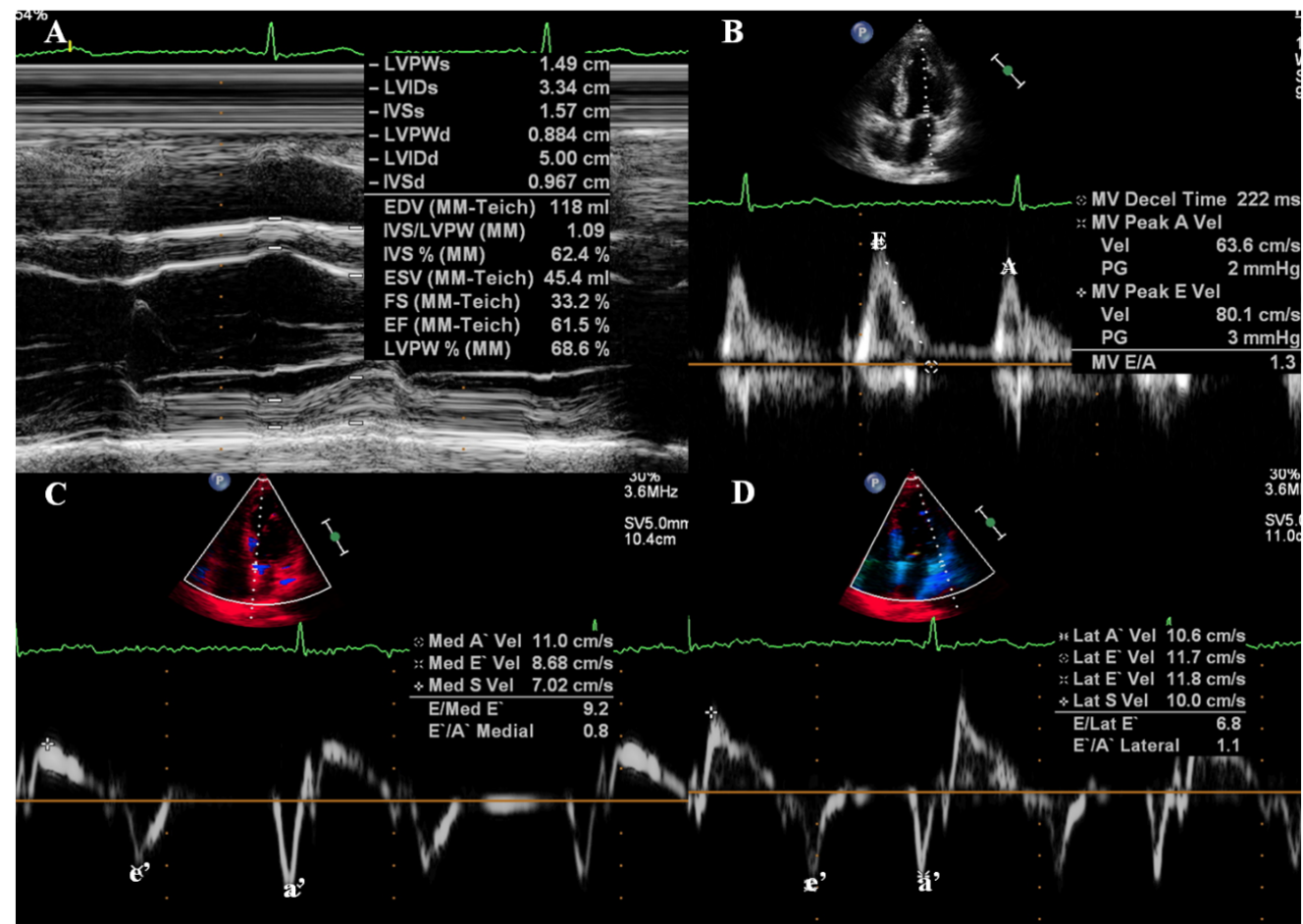

Figure 1. 1A - M-mode echocardiography revealing the results of measurements of the interventricular septum thickness, posterior wall thickness, left ventricular diastolic diameters in telediástole and left ventricular systolic diameter in telesystole; 1B - pulsed Doppler with the cursor placed just above the mitral valve showing the results of the early diastolic peak flow velocity (E) and late diastolic peak flow velocity (A), 1C and 1D Doppler tissue with the cursor placed on the septal and lateral mitral annulus respectively revealing the result of measurements of the early diastolic peak wave velocity (e'), and late diastolic peak velocity wave (a') 
or DD grade III) and "mild DD / Age" (for all patients with parameters compatible with altered relaxation, it being not possible to distinguish between mild diastolic dysfunction or age-specific changes), according to the recommendations for assessment of left ventricular diastolic function (2009) [11].

Statistical analysis: data are presented as mean and standard deviation, and the frequency as percentage. Calculations were performed in a calculation table in Excel for Windows.

\section{Results}

The sociodemographic and clinical characteristics are shown in (Table 1). As we can see, 84 patients were included in the study, being 33 (39\%) males and 51 (61\%) females, the mean age was $52.7 \pm 13$, 4 years. The mean SBP and DBP are $142.8 \mathrm{mmHg}$ and $85 \mathrm{mmHg}$, respectively. It should be noted that $41 \%$ of patients have been diagnosed for less than one year and in only $24 \%$ of patients hypertension was considered controlled. Analysis of the other CVRF/comorbidities showed that they are present in $51 \%$ of patients with special emphasis on the family history of hypertension that accounted for 39\%. With regard to BMI, we emphasized that only $37 \%$ of the patients were normal weight, $42 \%$ were overweight and $18 \%$ were obese.

The echocardiographic parameters presented in (Table 2) show that $87 \%$ of patients had normal left ventricular systolic function. In contrast, left ventricular diastolic dysfunction was present in $64 \%$ of patients: mild in $37 \%$, mild vs associated with age in $9 \%$, moderate in $12 \%$ and severe in $6 \%$. The geometric patterns of the left ventricle, illustrated in (Figure 2), show that the predominant geometric pattern in the present study was $\mathrm{CH}$ in $49 \%$ of patients, followed by EH and CR in $20 \%$ and $17 \%$ respectively.

Table 1. Sociodemographic and clinical characteristics of the studied population Sociodemographic and clinical characteristics of the studied population (n-84)

\begin{tabular}{|l|c|c|}
\hline \multicolumn{3}{|l|}{ Sociodemographic and clinical characteristics of the studied population (n-84) } \\
\hline Variables & $\mathrm{N}$ & Interval \\
\hline Mean age & 84 & $18-95$ \\
\hline F & $52,7(13,4)$ & \\
\hline M & $51(60,7 \%)$ & $1,2-2,3$ \\
\hline BS $\left(\mathrm{m}^{2}\right)$ & $33(39,3 \%)$ & $17,0-37,2$ \\
\hline BMI $\left(\mathrm{Kg} / \mathrm{m}^{2}\right)$ & $1,79 \pm 0,21$ & \\
\hline Underweight & $26,0 \pm 4,5$ & \\
\hline Normal weight & $3(3,5 \%)$ & \\
\hline overweight & $31(36,9 \%)$ & \\
\hline Obesity & $35(41,6 \%)$ & \\
\hline Duration of the SAH & $15(17,8 \%)$ & \\
\hline$<1$ year & & \\
\hline $1 \mathrm{t} 5$ years & $41(40,8 \%)$ & \\
\hline$>5$ years & $16(19,0 \%)$ & \\
\hline SBP mmHg & $27(32,1 \%)$ & $60-210$ \\
\hline DBP mmHg & $142,82 \pm 21,9$ & \\
\hline Controlled BP & $85,1 \pm 13,35$ & \\
\hline CVRF/Comorbidities & $29,0(24,52 \%)$ & \\
\hline Family history & $43(51,2 \%)$ & \\
\hline smoking & $33(39,3 \%)$ & \\
\hline Diabetes mellitus & $2(2,38 \%)$ & \\
\hline Dyslipidemia & $4(4,76 \%)$ & \\
\hline CKD & $5(5,95 \%)$ & \\
\hline & $6(7,14)$ & \\
\hline
\end{tabular}

F - female, M- male, BS - body surface, BMI - body mass index, BP - blood pressure, CKD - chronic kidney disease, CVRF - cardiovascular risk factors, DBP - diastolic blood pressure, SBP - systolic blood pressure, SAH - systemic arterial hypertension
Table 2. Echocardiographic and Doppler Study Parameters

\begin{tabular}{|l|c|c|}
\hline \multicolumn{2}{|l|}{ Echocardiographic and Doppler Study Parameters } & Interval \\
\hline Variable & Mean (SD) & $7-21$ \\
\hline IVST $(\mathrm{mm})$ & $12,6 \pm 2,8$ & $7-16$ \\
\hline PWT $(\mathrm{mm})$ & $11,4 \pm 2,3$ & $37-73$ \\
\hline LVTDD $(\mathrm{mm})$ & $49,0 \pm 6,4)$ & $101-606$ \\
\hline LVM $(\mathrm{g})$ & $279,0 \pm 106,7$ & $56-366$ \\
\hline LVMI (g/m $\left.{ }^{2}\right)$ & $159,1 \pm 66,1$ & $0,28-0,86$ \\
\hline RWT & $0,47 \pm 0,2$ & $7-68$ \\
\hline SF $(\%)$ & $37,6 \pm 10,8$ & $16-86$ \\
\hline LVEF (\%) & $65,4 \pm 14,3$ & $0,4-4,3$ \\
\hline LAI ml/m ${ }^{2}$ & $38,4 \pm 12,6$ & $2,7-18,3$ \\
\hline E/A & $1,3 \pm 0,78$ & \\
\hline E/e' & $6,4 \pm 2,97$ & \\
\hline Left ventricular systolic function & & \\
\hline Preserved & $73(86,9 \%)$ & \\
\hline Slightly compromised & $5(5,9 \%)$ & \\
\hline moderately compromised & $3(3,6 \%)$ & \\
\hline severely compromised & $3(3,6 \%)$ & \\
\hline Left ventricular diastolic function & & \\
\hline Normal & $30(35,7 \%)$ & \\
\hline Mild DD & $31(36,9 \%)$ & \\
\hline "Mild DD/Age" & $8(9,5 \%)$ & \\
\hline Moderate DD & $10(11,9 \%)$ & \\
\hline Severe DD & $5(5,9 \%)$ & \\
\hline & & \\
\hline
\end{tabular}

DD diastolic dysfunction IVST - interventricular septal thickness, LVDD - left ventricular diastolic diameter, LVEF - left ventricular ejection fraction, LVM - left ventricular mass LVMI - left ventricular mass index LAI - left atrial index SF PWT - posterior wall thickness, RWT - relative wall thickness.

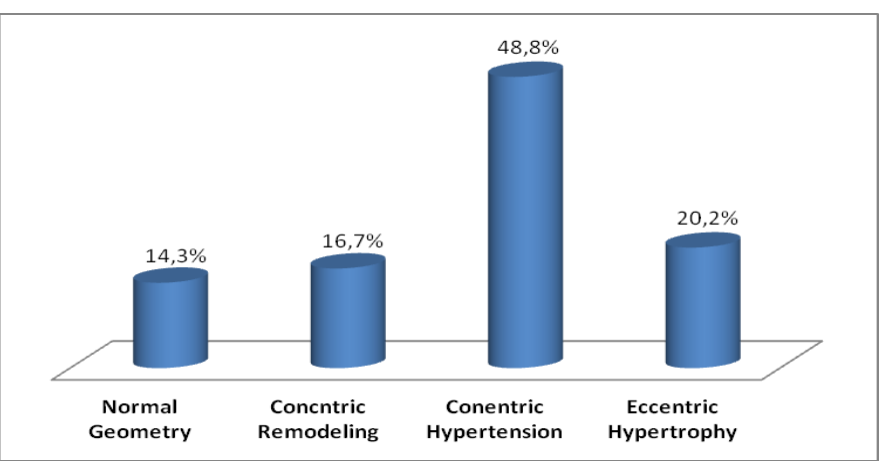

Figure 2. Prevalence of geometric patterns in the population studied (n-84)

\section{Discussion}

The objective of the present study was to evaluate the prevalence of the various geometric patterns in Angolan hypertensive patients, as well as to describe sociodemographic, clinical and echocardiographic aspects of the study population. Our main results showed that $\mathrm{CH}$ pattern was found in the majority of the patients; Second, $64 \%$ of the study population had some degree of diastolic dysfunction and third, only $1 / 4$ of the patients had controlled hypertension.

The combined use of LVMI and RWT allows the distinction of four geometric patterns [4]. Our study showed that $\mathrm{CH}$ was the most common pattern, occurring in $49 \%$ of patients, which is in agreement with most studies conducted in sub-Saharan Africa (Table 3) [12-19]. Aje et al. observed that $28 \%$ of patients with newly diagnosed hypertension exhibited the geometric pattern of $\mathrm{CH}$, while $18 \%$ demonstrated $\mathrm{EH}$ [12]. In turn, Adamu et al. observed that $38 \%$ of patients with newly diagnosed hypertension exhibited the $\mathrm{CH}$ pattern followed by $\mathrm{EH}$ in $25 \%$ of patients [13]. Akintunde et al in treated hypertensive patients 
Table 3. Prevalence of LV geometric patterns in hypertensive patients in Africa

\begin{tabular}{|l|c|c|c|c|}
\hline \% of LV geometric patterns in hypertensive patients in Africa \\
\hline $\begin{array}{l}\text { Auhtors } \\
\text { (Year) }\end{array}$ & $\begin{array}{c}\text { NG } \\
\text { N(\%) }\end{array}$ & $\begin{array}{c}\text { CR } \\
\text { N(\%) }\end{array}$ & $\begin{array}{c}\text { CH } \\
\mathbf{N}(\%)\end{array}$ & $\begin{array}{c}\text { EH } \\
\mathbf{N}(\%)\end{array}$ \\
\hline Aje et al. (2006) & $28(28,0)$ & $26(26,0)$ & $28(28,0)$ & $18(18,0)$ \\
\hline Adamu et al. (2009) & $15(15,3)$ & $33(22,0)$ & $57(38,0)$ & $37(24,7)$ \\
\hline Akitunde et al. (2010) & $30(16)$ & $53(28,2)$ & $72(38,3)$ & $33(17,5)$ \\
\hline Karaye et al. (2011) & $24(16,9)$ & $26(18,3)$ & $38(26,8)$ & $54(38,0)$ \\
\hline Akitunde et al. (2011) & $29(17,7)$ & $43(16,2)$ & $68(41,5)$ & $24(14,6)$ \\
\hline Ajayi et al. (2011) & $68(52,3)$ & $38(29,2)$ & $12(9,2)$ & $12(9,2)$ \\
\hline Silangei et al. (2012) & $68(30,0)$ & $45(19,8)$ & $64(28,2)$ & $50(22,0)$ \\
\hline Adebayo et al. (2013) & $186(18,2)$ & $488(47,8)$ & $237(23,2)$ & $109(10,7)$ \\
\hline Savarino et al. (actual Série) & $12(14,3)$ & $14(16,7)$ & $41(48,8)$ & $17(20,2)$ \\
\hline
\end{tabular}

in two consecutive series found that the $\mathrm{CH}$ was the main geometric pattern found in $38.3 \%$ and $41.5 \%$ respectively [14,17]. In contrast, Silangei et al., In Tanzania, observed that the NG was the most frequent geometric pattern (30\%) followed by $\mathrm{CH}(28 \%)$, hypertensive patients under treatment and untreated patients were included in this study [18]. Adebayo et al. report CR as the main pattern found followed by $\mathrm{CH}$ in a series of 1020 hypertensive patients [19]. With the exception of the Hajayi et al. study [15], which found a NG pattern in $52 \%$ of patients, the percentage of the NG pattern in the remaining series ranged from 15 to $30 \%$. In the present study, we found this pattern in only $14 \%$ of patients.

It can be assumed that the changes observed in our study resulted from uncontrolled hypertension since only $25 \%$ of our patients had controlled hypertension. Studies comparing geometric patterns between treated and controlled patients and uncontrolled patients are required to answer this question. However, it is known that patients with $\mathrm{CH}$ have a higher correlation with persistently elevated blood pressure levels during ambulatory blood pressure monitoring. On the other hand, LV remodeling seems to be influenced by other factors such as: ethnicity, gender, presence of diabetes mellitus, previous myocardial infarction obesity, chronic renal failure and metabolic syndrome [20]. All these factors can justify the variability in the geometric patterns found among the several studies analyzed here. The methodology used in the various studies, using several formulas to calculate LVM and RWT, as well as several cut-off values for the definition of geometric patterns, is another important aspect to take into account [21].

In Sub-Saharan Africa several studies have evaluated the relationship between geometric patterns and left ventricular function $[13,14,16-18]$. Regarding diastolic function, the data found in our study were very similar to the results reported by Adamu et al. [13] where diastolic dysfunction was found in $62 \%$ of hypertensive patients: $52.7 \%$ had alterations in ventricular relaxation (mild DD), $8 \%$ had a pseudonormal pattern (moderate DD) and $1.3 \%$ had a restrictive pattern (severe DD). Only about $38 \%$ of patients had normal diastolic function. In addition, these authors found significant differences in diastolic function between the various geographic patterns and in the univariate analysis, the $\mathrm{E}$ wave and the $\mathrm{E} / \mathrm{A}$ ratio correlated significantly but inversely with the posterior wall thickness LVMI and the relative wall thickness. S wave of pulmonary vein flow and S D ratio were negatively correlated with LVMI. Multivariate of multiple regression analysis maintained the correlation between $\mathrm{E}$ wave, pulmonary venous $\mathrm{S}$ wave, E/A ratio and LVMI and RWT. Adebayo et al. [19] also found that the Doppler study parameters showed some degree of diastolic dysfunction in hypertensive patients with abnormal LV geometric patterns. These parameters included the E/A ratio, E wave deceleration time, and isovolumetric relaxation time. Patients with concentric hypertrophy showed significant differences in all three parameters compared to those with normal geometry.

Regarding left ventricular systolic function, several authors showed that patients with eccentric hypertrophy had statistically lower parameters of systolic function (ejection fraction and shortening) compared to other geometric patterns $[14,16,18,19]$. Preliminary data from a sub-analysis of our study indicate that there are significant differences in left ventricular systolic and diastolic function between the various geometric patterns (data not shown).

\section{Clinical importance}

Variable degrees of morbidity and mortality are associated with ventricular geometry patterns with worse prognosis for patients with concentric hypertrophy, eccentric hypertrophy and concentric remodeling. Koren et al. [5] followed 280 patients with systemic arterial hypertension for 10.2 years and found, in a univariate analysis, that ventricular hypertrophy is a predisposing factor of cardiovascular events. In multivariate analysis adjusted for sex, age, total cholesterol and systolic and diastolic blood pressure, ventricular hypertrophy was a predictor of cardiovascular events, cardiac death and global mortality. Regarding the geometric pattern, patients with concentric hypertrophy also had higher incidence of cardiovascular events in this group. Muiesan et al. [22] also showed that cardiovascular events were more frequent in patients with $\mathrm{HC}$, implying it as a dangerous adaptive pattern for hypertension.

Several investigations show that ventricular hypertrophy may regress with therapeutic measures [22,23]. Although this regression results in an improvement in the filling pattern and left ventricular performance, data indicating that regression of hypertrophy is a determinant factor for the improvement of hypertensive mortality and morbidity are controversial [20].

In summary, in the present study, the vast majority of patients presented an altered geometric pattern, with concentric hypertrophy being the most common pattern followed by eccentric hypertrophy. These data highlight the severity of hypertensive patients in Angola and reinforce the need for a more aggressive approach in early detection, appropriate institution of treatment and follow-up of our patients with hypertension.

\section{Conclusion}

The results show that, in our hypertensive population, concentric and eccentric hypertrophies are the most frequent geometric patterns. Diastolic dysfunction is present in most patients. The need for longitudinal studies assessing the prognostic value of geometric patterns in hypertensive patients in Angola, as well as their relationship with left ventricular function is imperative.

Contribution of the authors: Pereira SV- Elaborated the conception and design of the study, participated in the analysis of the data, as well as the writing of the manuscript. Feijão A - Participated in the collection and analysis of the data, as well as the writing of the manuscript. Morais $\mathrm{H}$ Participated in data analysis, bibliographical research as well as the writing of the manuscript and reviewed the final version of the manuscript and approve it for publication

\section{Conflict of interest}

All the authors have no conflict of interest. 


\section{References}

1. Pires J, Sebastião Y, Langa A, Nery S (2013) Hypertension in Northern Angola: prevalence, associated factors, awareness, treatment and control. BMC Public Health 13: 90 .

2. Levy D, Garrison RJ, Savage DD, Kannel WP, Castelli WP (1990) Prognostic implications of echocardiography determined left ventricular mass in the Framingham Heart Study. N Engl J Med 322: 1561-1566. [Crossref]

3. Ghali JK, Liao Y, Simmons B, Castaner A, Cao G, et al. (1992) The prognostic role of left ventricular hypertrophy in patients with or without coronary artery disease. Ann Intern Med 117: 826-831. [Crossref]

4. Ganau A, Devereux RB, Roman MJ, de Simone G, Pickering TG, et al. (1992) Patterns of left ventricular hypertrophy and geometric remodeling in essential hypertension. $J$ Am Coll Cardiol 19: 1550-1558. [Crossref]

5. Koren MJ1, Devereux RB, Casale PN, Savage DD, Laragh JH (1991) Relation of left ventricular mass and geometry to morbidity and mortality in uncomplicated essential hypertension. Ann Intern Med 114: 345-352. [Crossref]

6. Verdecchia P, Schillaci G, Borgioni C, Ciucci A, Battistelli M, et al. (1995) Adverse prognostic significance of concentric remodeling of the left ventricle in hypertensive patients with normal left ventricular mass. $J$ Am Coll Cardiol 25: 871-878. [Crossref]

7. Lang RM, Bierig M, Devereux RB, Flachskampf FA, Foster E, et al. (2005) Recommendations for chamber quantification: a report from the American Society of Echocardiography's Guidelines and Standards Committee and the Chamber Quantification Writing Group, developed in conjunction with the European Association of Echocardiography, a branch of the European Society of Cardiology. J Am Soc Echocardiogr 18:1440-1463. [Crossref]

8. Quiñones MA, Otto CM, Stoddard M, Waggoner A, Zoghbi WA (2002) Recommendations for Quantification of Doppler Echocardiography: A Report From the Doppler Quantification Task Force of the Nomenclature and Standards Committee of the American Society of Echocardiography. J Am Soc Echocardiogr 15:167-184. [Crossref]

9. Devereux RB, Alonso DR, Lutas EM, Gottlieb GJ, Campo E, et al. (1986) Echocardiographic assessment of left ventricular hypertrophy: comparison to necropsy findings. Am J Cardiol 57: 450-458. [Crossref]

10. Levy D, Savage DD, Garrison RJ, Anderson KM, Kannel WB, et al. (1987) Echocardiographic criteria for left ventricular hypertrophy: The Framingham Heart Study. Am J Cardiol 59: 956-960. [Crossref]

11. Nagueh SF, Appleton CP, Gillebert TC, Marino PN, Oh JK, Smiseth OA, et al. (2009) Recommendations for the Evaluation of Left Ventricular Diastolic Function by Echocardiography: An Update from the American Society of Echocardiography and the European Association of Cardiovascular Imaging. J Am Soc Echocardiogr 22: 107133. [Crossref]
12. Aje A, Adebiyi AA, Oladapo OO, Dada A, Ogah OS, et al. (2006) Left ventricular geometric patterns in newly presenting Nigerian hypertensives: an echocardiographic study. BMC Cardiovasc Disord 6: 4. [Crossref]

13. Adamu UG, Kolo PM, Katibi IA, Opadijo GO, Omotosho AB, et al. (2009) Relationship between left ventricular diastolic function and geometric patterns in Nigerians with newly diagnosed systemic hypertension. Cardiovasc J Afr 20: 173-177. [Crossref]

14. Akintunde AA, Familoni OB, Akinwusi PO, Opadijo OG (2010) Relationship between left ventricular geometric pattern and systolic and diastolic function in treated Nigerian hypertensives. Cardiovasc J Afr 21: 21-25. [Crossref]

15. Ajayi OE, Ajayi EA, Akintomide OA, Adebayo RA, Ogunyemi SA, et al. (2011) Ambulatory blood pressure profile and left ventricular geometry in Nigerian hypertensives. J Cardiovas Dis Res 2: 164-171. [Crossref]

16. Karaye KM (2011) Relationship between Tei Index and left ventricular geometric patterns in a hypertensive population: a cross-sectional study. Cardiovasc Ultrasound 9: 21 .

17. Akintunde AA, Akinwusi PO, Opadijo GO (2011) Relationship between Tei index of myocardial performance and left ventricular geometry in Nigerians with systemic hypertension. Cardiovasc J Afr 22: 124-127. [Crossref]

18. Silangei LK, Maro VP, Diefenthal H, Kapanda G, Dewhurst M, et al. (2012) Assessment of left ventricular geometrical patterns and function among hypertensive patients at a tertiary hospital, Northern Tanzania. BMC Cardiovasc Disord 12: 109.

19. Adebayo RA, Bamikole OJ, Balogun MO, Akintomide AO, Adeyeye VO, et al. (2013) Echocardiographic assessment of left ventricular geometric patterns in hypertensive patients in Nigeria. Clin Med Insights Cardiol 7: 161-167. [Crossref]

20. Oktay AA, Lavie CJ, Milani RV, Ventura HO, Gilliland YE, et al. (2016) Curren Perspectives on Left Ventricular Geometry in Systemic Hypertension. Prog Cardiovasc Dis 59: 235-246. [Crossref]

21. Ferreira Filho PRP (2012) Padrões de hipertrofia e geometria do ventrículo esquerdo pela ecocardiografia transtorácica. Rev Bras Ecocardiog Imagem Cardiovasc 25: $103-$ 115 .

22. Muiesan ML, Salvetti M, Monteduro C, Bonzi B, Paini A, et al. (2004) Left ventricular concentric geometry during treatment adversely affects cardiovascular prognosis in hypertensive patients. Hypertension 43: 731-738. [Crossref]

23. Salvetti M, Paini A, Bertacchini F, Stassaldi D, Aggiusti C, et al. (2018) Changes in left ventricular geometry during antihypertensive treatment. Pharmacol Res 134: 193-199. [Crossref]

Copyright: (C2019 Pereira SV. This is an open-access article distributed under the terms of the Creative Commons Attribution License, which permits unrestricted use, distribution, and reproduction in any medium, provided the original author and source are credited. 